\title{
Abstract
}

\section{Pathological Characteristics and Demographics of Prostate Carcinoma Treated at a Tertiary Care Hospital in Sri Lanka}

Gajasinghe $\mathrm{S}^{1}$, Sasikumar $\mathrm{S}^{1}$, Wijayarathna $\mathrm{KSN}^{1}$, Karunaratne $\mathrm{KAMS}^{1}$, Gobi $\mathrm{U}^{1}$, Abeygunasekera $\mathrm{A} \mathrm{M}^{1}$

${ }^{1}$ Colombo South Teaching Hospital

Key words: prostate cancer, pathological characteristics

\section{Introduction \\ Prostate cancer is the most common non-cutaneous cancer among males in Sri Lanka and it accounts for almost $10 \%$ of cancer-related deaths in males. \\ Methodology \\ In our study we are assessed the pathological characteristics and demographics of prostate cancer diagnosed in our unit. It was a prospective analytical study which included all the patients diagnosed with prostate cancer during the study period $(01 / 01 / 2015$ to $30 / 09 / 2015)$. The history, examination and investigations indicated by clinical findings of the patients were used for data collection.}

\section{Results}

Study included 60 patients with average age of 72 years. Commonest presentation was acute urinary retention. Different variants of adenocarcinomas were the leading pathological phenotype while one patient had ductal carcinoma of the prostate. Only two patients had a PSA level less than $4 \mathrm{ng} / \mathrm{ml}$. Four patients had a PSA level less than $15 \mathrm{ng} / \mathrm{ml}$. Bilateral orchidectomy remained the leading method of treatment. One patient had negative histology on subsequent TURP.

Corresponding Author: Seneth Gajasinghe, Email:<seneth1983@gmail.com>

Presentation at the $5^{\text {th }}$ biennial academic sessions of the Postgraduate institute of Medicine on 06 October 2016

Competing Interests: Authors have declared that no competing interests exist. 